\title{
Laypersons' evaluation of health: an exploratory study of an Australian population
}

\author{
Anthony Worsley
}

\begin{abstract}
The importance of 33 aspects of health was evaluated by 677 people as part of a postal random population survey conducted in Adelaide, South Australia. Principal factors analysis suggested that the respondents' evaluations could be represented along four dimensions to do with: the avoidance of illness; feeling healthy; healthy lifestyle; and disease prevention activities. Generally, women, persons in older age groups, and persons in lower social status and education groups evaluated health more highly than others. These and other findings suggest that health evaluations depend upon illness experience and social roles. These findings have implications for health education, mass communication and medical practice.
\end{abstract}

Health is an all encompassing concept which has many connotations. Many people work in health professions, many carry out health research, and many more strive to restore or maintain their health. But what is health?

The concept can refer to many end points, ranging from the absence of disease to quality of life. ${ }^{1}$ For example, orthodox medicine places much emphasis on the treatment of disease ${ }^{2}$ and a much lesser emphasis on the prevention of disease. Alternatively non-medical health practitioners tend to be more concerned with subjective aspects of health, viewing it holistically in terms of wellbeing and lifestyle. ${ }^{3}$

Although health is often interpreted intuitively by health professionals and more formally by others $\left(\mathrm{eg}^{4}\right)$ there have been few studies of laypersons' concepts of health. Self reported morbidity and function $\left(\mathrm{eg}^{5}\right)$ and perceived social determinants of health ${ }^{6}$ have been addressed, but lay evaluations of the various aspects of health remain largely unknown. In other words, little is known of the relative importance people place on the different components of health.

Therefore the main aim of the present study was to describe lay evaluations of a variety of aspects of health, based on a random sample of the adult population. Such information may enable some assessment to be made of the capacity of existing health services to meet consumer health goals.

A second aim followed from the first: the investigation of the ways in which members of sociodemographic groups evaluate aspects of health. A general familiarity hypothesis was proposed, that members of groups which have higher prevalence of illness (mortality and morbidity rates) may perceive certain health issues to be more salient (or important) than people who belong to groups with lower prevalences of illness. That is, familiarity with health problems (deprivation of health) increases the perceived salience of related health perceptions.

It was expected that women and people in older, less educated, or lower social status groups would evaluate most aspects of health more highly than men, or people in younger, more educated, or higher social status groups. These expectations ensued from the following observations: (1) women report greater symptomatology ${ }^{7}$ and appear to have higher morbidity rates than men; ${ }^{8}$ (2) older age groups have higher mortality rates, and possibly higher morbidity rates than younger age groups (eg9); and (3) groups with low social status and less education appear to have higher mortality and morbidity rates than groups with higher social status and better education. ${ }^{9-12}$

Further, it is likely that experience of illness or limited personal health is not the only factor which might influence the perceived salience of health. Some social roles may have similar effects. For example, parenthood imposes a responsibility to care for children and exposes parents to particular aspects of (children's) health and illness. Thus parents are likely to be more aware of children's ailments than other adults and so they may value related aspects of health more highly than non-parents.

\section{Methods}

\section{SUBJECTS AND PROCEDURE}

One thousand men and women were selected at random from the electoral rolls for the Adelaide metropolitan area during November 1983. Survey booklets were mailed to these people at their last known address. After two weeks, nonrespondents were sent a reminder letter; two weeks later a replacement booklet, and two weeks later, a final reminder was mailed to the remaining non-respondents. The survey booklets were designed and administered according to general recommendations suggested by Dillman ${ }^{13}$ and modifications made by us in previous surveys.

\section{THE INSTRUMENT}

The survey instrument was designed to examine the relationships between health beliefs and dietary supplementation practices. It consisted of 12 half A4 size pages which listed questions about health status, the reliability of sources of health information, and the use of dietary supplements and their perceived consequences, as well as questions about the perceived importance of 33 


\begin{tabular}{|c|c|c|c|c|c|c|c|c|c|c|c|c|c|c|c|c|}
\hline & \multicolumn{2}{|c|}{$\begin{array}{l}\text { Sex } \\
\text { differences }\end{array}$} & \multicolumn{4}{|c|}{ Age group differences } & \multicolumn{4}{|c|}{ Educational differences } & \multicolumn{3}{|c|}{$\begin{array}{l}\text { Social status } \\
\text { differences }\end{array}$} & \multicolumn{3}{|c|}{$\begin{array}{l}\text { Dietary supplementation } \\
\text { differences }\end{array}$} \\
\hline & Men & Women & $<30$ & $31-50$ & $51-7$ & $0>70$ & $\begin{array}{l}\text { Mainly } \\
\text { Primary }\end{array}$ & $\begin{array}{l}\text { High } \\
\text { School }\end{array}$ & $\begin{array}{l}\text { Trades }+ \\
\text { Technical }\end{array}$ & Tertiary & High & MiddleI & eLow & Regular & Irregular & Non \\
\hline $\begin{array}{l}\text { 1. Having regular medical checkups } \\
\text { 2. Eating natural foods } \\
\text { 3. Taking regular exercise } \\
\text { 4. Eating regular meals } \\
\text { 5. Living in a non-polluted environment } \\
\text { 6. Getting enough sleep } \\
\text { 7. Having good social relationships } \\
\text { 8. Eating plenty of fruit and vegetables } \\
\text { 9. Lowering your blood fat levels } \\
\text { 10. Feeling healthy } \\
\text { 11. Feeling energetic } \\
\text { 12. Looking healthy } \\
\text { 13. Having healthy looking skin and hair } \\
\text { 14. Having regular bowels } \\
\text { 15. Becoming healthier } \\
\text { 16. Doing things to prevent dietary }\end{array}$ & $\begin{array}{l}45 \\
41 \\
56 \\
55 \\
45 \\
56 \\
36 \\
55 \\
37 \\
63 \\
54 \\
49 \\
46 \\
59 \\
54\end{array}$ & 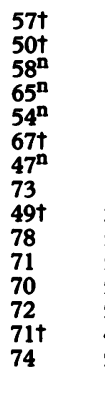 & $\begin{array}{l}33 \\
31 \\
51 \\
51 \\
31 \\
53 \\
38 \\
52 \\
25 \\
56 \\
50 \\
52 \\
53 \\
46 \\
50\end{array}$ & $\begin{array}{l}52 \\
45 \\
57 \\
61 \\
53 \\
60 \\
37 \\
64 \\
43 \\
74 \\
65 \\
60 \\
58 \\
67 \\
71\end{array}$ & $\begin{array}{l}68 \\
59 \\
64 \\
67 \\
64 \\
72 \\
50 \\
78 \\
60 \\
83 \\
76 \\
70 \\
68 \\
80 \\
71\end{array}$ & $\begin{array}{l}76 \\
74 \\
62 \uparrow \\
79 \dagger \\
70 \\
74 \dagger \\
67 \\
85 \\
67 \\
86 \\
71 \\
74 \uparrow \\
71^{n} \\
85 \\
77\end{array}$ & $\begin{array}{l}61 \\
52 \\
50 \\
68 \\
62 \\
70 \\
48 \\
76 \\
51 \\
76 \\
70 \\
70 \\
67 \\
79 \\
74\end{array}$ & $\begin{array}{l}57 \\
49 \\
57 \\
62 \\
53 \\
65 \\
44 \\
68 \\
47 \\
74 \\
64 \\
63 \\
65 \\
67 \\
69\end{array}$ & $\begin{array}{l}47 \\
43 \\
63 \\
62 \\
43 \\
53 \\
37 \\
60 \\
41 \\
70 \\
65 \\
61 \\
58 \\
63 \\
58\end{array}$ & $\begin{array}{l}30 \\
33^{\mathrm{n}} \\
62 \\
43 \\
34 \\
53 t \\
38^{\star} \\
48 \\
26 \\
60^{\mathrm{n}} \\
53 t \\
41 \\
42 \\
43 \\
49\end{array}$ & $\begin{array}{l}37 \\
42 \\
58 \\
45 \\
40 \\
54 \\
37 \\
52 \\
36 \\
67 \\
61 \\
45 \\
46 \\
54 \\
53\end{array}$ & $\begin{array}{l}47 \\
40 \\
53 \\
60 \\
44 \\
60 \\
37 \\
57 \\
34 \\
64 \\
56 \\
58 \\
57 \\
60 \\
60\end{array}$ & $\begin{array}{l}61 \\
54 t \\
60^{\mathrm{n}} \\
66 \\
58 \\
68^{\mathrm{n}} \\
51^{\star} \\
76 \\
55 \\
81 \dagger \\
72 \dagger \\
68 t \\
68^{\star} \\
74 \\
73 t\end{array}$ & $\begin{array}{l}84 \\
88 \\
94 \\
96 \\
87 \\
97 \\
85 \\
98 \\
85 \\
96 \\
95 \\
93 \\
92 \\
97 \\
94\end{array}$ & $\begin{array}{l}81 \\
82 \\
95 \\
87 \\
85 \\
99 \\
85 \\
98 \\
79 \\
97 \\
99 \\
91 \\
94 \\
91 \\
96\end{array}$ & $\begin{array}{l}75 \dagger \\
74 \\
86 \\
90 \\
79 \dagger \\
94^{n} \\
81^{n} \\
90 \\
66 \\
95^{n} \\
92 t \\
89^{\star} \\
87 \\
88 \\
88\end{array}$ \\
\hline $\begin{array}{l}\text { deficiencies } \\
\text { 17. Doing things to prevent bowel cancer } \\
\text { 18. Doing things to prevent other cancers } \\
\text { 19. Doing things to prevent heart }\end{array}$ & $\begin{array}{l}42 \\
48 \\
48\end{array}$ & $\begin{array}{l}58 \\
62 \\
63\end{array}$ & $\begin{array}{l}34 \\
39 \\
41\end{array}$ & $\begin{array}{l}51 \\
56 \\
57\end{array}$ & $\begin{array}{l}65 \\
69 \\
67\end{array}$ & $\begin{array}{l}74 \\
81 \\
81\end{array}$ & $\begin{array}{l}61 \\
62 \\
62\end{array}$ & $\begin{array}{l}55 \\
65 \\
66\end{array}$ & $\begin{array}{l}47 \\
48 \\
46\end{array}$ & $\begin{array}{l}34 \\
36 \\
37\end{array}$ & $\begin{array}{l}39 \\
44 \\
44\end{array}$ & $\begin{array}{l}45 \\
47 \\
46\end{array}$ & $\begin{array}{l}60 \\
67 \\
68\end{array}$ & $\begin{array}{l}90 \\
80 \\
74\end{array}$ & $\begin{array}{l}84 \\
75 \\
79\end{array}$ & $\begin{array}{l}68 \\
67 \\
70\end{array}$ \\
\hline $\begin{array}{l}\text { disease/stroke } \\
\text { 20. Avoiding colds and minor infections } \\
\text { 21. Avoiding a build-up of toxic }\end{array}$ & $\begin{array}{l}53 \\
31\end{array}$ & $\begin{array}{l}67 \\
45\end{array}$ & $\begin{array}{l}44 \\
26\end{array}$ & $\begin{array}{l}61 \\
35\end{array}$ & $\begin{array}{l}75 \\
50\end{array}$ & $\begin{array}{l}84 \\
72\end{array}$ & $\begin{array}{l}66 \\
53\end{array}$ & $\begin{array}{l}68 \\
39\end{array}$ & $\begin{array}{l}56 \\
35\end{array}$ & $\begin{array}{l}43 \\
19\end{array}$ & $\begin{array}{l}51 \\
20\end{array}$ & $\begin{array}{l}53 \\
33\end{array}$ & $\begin{array}{l}71 \\
49 t\end{array}$ & $\begin{array}{l}88 \\
84\end{array}$ & $\begin{array}{l}90 \\
77\end{array}$ & $\begin{array}{l}77 \\
71\end{array}$ \\
\hline $\begin{array}{l}\text { chemicals } \\
\text { 22. Avoiding abdominal discomfort } \\
\text { 23. Avoiding nausea and/or vomiting } \\
\text { 24. Avoiding diarrhoea } \\
\text { 25. Avoiding muscle or joint pains } \\
\text { 26. Avoiding stress or depression } \\
\text { 27. Avoiding kidney stones or gallstones } \\
\text { 28. Avoiding the effects of hangovers } \\
\text { 29. Avoiding salt and salty foods } \\
\text { 30. Avoiding fat and fatty foods } \\
\text { 31. Avoiding sugar and sugary foods } \\
\text { 32. Not feeling tired } \\
\text { 33. Not becoming ill or unhealthy }\end{array}$ & $\begin{array}{l}40 \\
41 \\
45 \\
45 \\
41 \\
53 \\
48 \\
42 \\
30 \\
31 \\
27 \\
40 \\
70\end{array}$ & $\begin{array}{l}48^{n} \\
52^{n} \\
58 t \\
48 t \\
53 t \\
64^{\star} \\
55^{n} \\
50^{n} \\
40 \\
43 \\
42 \\
61 \\
79\end{array}$ & $\begin{array}{l}27 \\
30 \\
35 \\
33 \\
34 \\
48 \\
35 \\
29 \\
27 \\
23 \\
24 \\
36 \\
63\end{array}$ & $\begin{array}{l}46 \\
45 \\
54 \\
53 \\
46 \\
58 \\
53 \\
49 \\
36 \\
36 \\
37 \\
57 \\
78\end{array}$ & $\begin{array}{l}58 \\
62 \\
65 \\
66 \\
61 \\
71 \\
63 \\
59 \\
41 \\
54 \\
44 \\
59 \\
84\end{array}$ & $\begin{array}{l}68 \\
78 \\
72 \\
84 \\
81 \\
78 \\
81 \\
69 \\
56 t \\
52 \\
36 \\
66 \\
85\end{array}$ & $\begin{array}{l}54 \\
61 \\
62 \\
63 \\
15 \\
66 \\
15 \\
66 \\
60 \\
59 \\
43 \\
61 \\
79\end{array}$ & $\begin{array}{l}48 \\
49 \\
57 \\
55 \\
20 \\
66 \\
20 \\
66 \\
58 \\
49 \\
35 \\
54 \\
80\end{array}$ & $\begin{array}{r}39 \\
48 \\
51 \\
56 \\
9 \\
55 \\
9 \\
55 \\
50 \\
45 \\
38 \\
49 \\
73\end{array}$ & $\begin{array}{r}30 \\
21 \\
26 \\
26 \\
4 \\
41 \\
4 \\
41 \\
28 \\
27 \\
26 \\
34 \\
60\end{array}$ & $\begin{array}{l}40 \\
32 \\
41 \\
42 \\
37 \\
52 \\
41 \\
41 \\
28 \\
29 \\
24 \\
48 \\
67\end{array}$ & $\begin{array}{l}38 \\
41 \\
47 \\
47 \\
45 \\
58 \\
47 \\
41 \\
29 \\
29 \\
27 \\
44 \\
71\end{array}$ & $\begin{array}{l}52^{\mathrm{n}} \\
56 t \\
60^{\mathrm{n}} \\
60^{\mathrm{n}} \\
54^{\mathrm{n}} \\
64^{\mathrm{n}} \\
59^{\mathrm{n}} \\
55 \dagger \\
44 \\
49 \\
45 \\
60^{\mathrm{n}} \\
81^{\star}\end{array}$ & $\begin{array}{l}79 \\
82 \\
81 \\
82 \\
80 \\
88 \\
88 \\
74 \\
81 \\
85 \\
83 \\
88 \\
96\end{array}$ & $\begin{array}{l}74 \\
84 \\
84 \\
82 \\
84 \\
93 \\
70 \\
70 \\
71 \\
85 \\
79 \\
93 \\
99\end{array}$ & $\begin{array}{l}65 t \\
77 t \\
75 t \\
76 \dagger \\
77 t \\
85^{\mathbf{n}} \\
70^{\mathbf{n}} \\
66^{\star} \\
61 \\
68 \\
61 \\
80 \\
89\end{array}$ \\
\hline
\end{tabular}

${ }^{\star} p<0.05 ; \mathrm{t}<0.01{ }^{n}=$ non-significant. All other differences $p \leqslant 0.001$ (two tailed test)

Table I Perceptions of the importance of health. Sex, age group,

educational, social status and dietary

supplementation group differences in the

respondents' endorsements of the "quite" and "very important" response categories. Values are percent of respondents in each demographic group. aspects of health. Details of the respondents' perceptions of the reliability of sources of health information are reported elsewhere. ${ }^{14}$

The 33 health items are listed in table I. These were selected from lists of ailments and disease which a previous survey had shown were prevalent in the general population, and health topics which were considered to be important by large numbers of respondents. ${ }^{715}$ In addition some of the items emerged from questions about the nature of health during pretesting of this and earlier questionnaires.

Respondents were asked to rate the importance of each of the 33 items by means of a seven point rating scale which ranged from $1=$ very unimportant, through $4=$ uncertain, to $7=$ very important. Early versions of the questionnaire were pretested on small groups of people to ensure that the questions and the closed response options were clearly expressed and meaningful to the respondents.

Information about the respondents' social background was also requested. This included details of the respondent's sex, age, occupation, education, living arrangements (such as the presence or absence of children under 18 years, living alone or with others), as well as details of dietary supplementation habits.

ANALYSIS

The data were analysed sequentially by univariate and multivariate techniques.

Several series of contingency table analyses were conducted on responses to each item, responses being grouped so that each series used one of the demographic (or respondent background variables) as a criterion variable over all respondents as well as, and within, each sex (eg, age group $\times$ response category). $\chi^{2}$ Tests were used to estimate significant differences in cell distributions. These are summarised in table II.

Principal factors analysis (with varimax rotation) was used to reduce a matrix of correlations between the 33 item response scores to a smaller number of representative dimensions or factors. This was an exploratory analysis carried out to examine whether several kinds of health importance existed within the respondents' perceptions, and if possible, to identify them.

The respondents' scores on each of these factors were calculated by summing the products of their response scores to each item by a factor coefficient. ${ }^{16}$ These scores were then analysed by two way analyses of variance in which the respondent's sex and one other background variable (eg, age group, presence or absence of children) were the independent variables (eg, age group $\times$ sex; educational group $\times$ sex). In this paper the results of the contingency table analyses are given more prominence because the ANOVAs generally confirmed the trends seen in these tables but gave less detail. The ANOVA results will be referred to only when they provide information which is not immediately apparent from the contingency tables. For the purposes of these analyses the independent variables were categorised as follows:

Age-Four groups: $<31,31-50,51-70,>70$ years

Educational background-Four groups: primary plus some high school, completed high school, trades and technical qualifications, tertiary qualifications.

Social status-Occupations were ranked according to Daniel's revision of Congalton's 


\begin{tabular}{|c|c|c|c|c|c|c|c|}
\hline $\begin{array}{ll}\text { Factor: } & 1 \\
\text { Eigenvalue: } & 13 \cdot 88 \\
\text { as percent variance: } 71 \cdot 0 & \\
\text { Provisional name: “Avoiding illness" }\end{array}$ & & $\begin{array}{l}2 \\
2 \cdot 43 \\
12 \cdot 4 \\
\text { "Being healthy" }\end{array}$ & & $\begin{array}{l}3 \\
1 \cdot 46 \\
7 \cdot 4 \\
\text { "Healthy lifestyle" } \\
\end{array}$ & & $\begin{array}{l}4 \\
1 \cdot 08 \\
5 \cdot 5 \\
\text { "Disease prevention" }\end{array}$ & \\
\hline $\begin{array}{l}\text { Doing things to prevent bowel cancer } \\
\text { Doing things to prevent other cancers } \\
\text { Doing things to prevent heart } \\
\text { disease/strokes } \\
\text { Avoiding colds and minor infections } \\
\text { Avoiding a build up of toxic } \\
\text { chemicals in your body } \\
\text { Avoiding abdominal discomfort } \\
\text { Avoiding nausea/vomiting } \\
\text { Avoiding diarrhoea } \\
\text { Avoiding muscle or joint pains } \\
\text { Avoiding stress or depression } \\
\text { Avoiding kidney stones or gallstones } \\
\text { Avoiding the effects of hangovers } \\
\text { Not feeling tired } \\
\text { Not becoming ill or unhealthy }\end{array}$ & $\begin{array}{l}48 \\
43 \\
\\
46 \\
59 \\
\\
56 \\
73 \\
81 \\
79 \\
76 \\
60 \\
71 \\
57 \\
43 \\
44\end{array}$ & $\begin{array}{l}\text { Feeling healthy } \\
\text { Feeling energetic } \\
\text { Looking healthy } \\
\text { Having healthy looking } \\
\text { skin and hair } \\
\text { Having regular bowels } \\
\text { Becoming healthier } \\
\text { Not feeling tired } \\
\text { Not becoming ill } \\
\text { or unhealthy }\end{array}$ & $\begin{array}{l}77 \\
78 \\
81 \\
\\
71 \\
44 \\
51 \\
41 \\
\\
46\end{array}$ & $\begin{array}{l}\text { Eating natural foods } \\
\text { Taking regular } \\
\text { exercise } \\
\text { Eating regular meals } \\
\text { Living in a non-polluted } \\
\text { environment } \\
\text { Getting enough sleep } \\
\text { Eating plenty of fruit } \\
\text { and vegetables } \\
\text { Lowering your blood } \\
\text { fat levels } \\
\text { Having regular bowels }\end{array}$ & $\begin{array}{l}62 \\
52 \\
56 \\
59 \\
43 \\
\\
62 \\
49 \\
45\end{array}$ & $\begin{array}{l}\text { Doing things to prevent } \\
\text { dietary deficiencies } \\
\text { Doing things to prevent } \\
\text { bowel cancer } \\
\text { Doing things to prevent } \\
\text { other cancers } \\
\text { Doing things to prevent } \\
\text { heart disease/strokes } \\
\text { Avoiding a build up of toxic } \\
\text { chemicals in your body } \\
\text { Avoiding kidney stones } \\
\text { or gallstones }\end{array}$ & $\begin{array}{l}51 \\
71 \\
76 \\
66 \\
39 \\
40\end{array}$ \\
\hline
\end{tabular}

Table II Results of the principal factors analysis (with varimax rotation) of the respondents' ratings of the importance of loadings expressed as whole numbers; loading less than $\mathbf{4 0}$ omitted). aspects of health (factor

social status scale for Australia. These were further categorised into three groups: high status (Congalton categories $1,2,3)$, middle status $(4,5)$, low status (6, 7 and unemployed). Housewives were allocated their spouse's/partner's ranks.

Dietary supplementation-Three groups: nonsupplementers, regular supplementers (using supplements more than once a week), and irregular supplementers (using them "now and again").

\section{Results}

Completed questionnaires were returned by 677 people, 51 refused to participate, and 98 questionnaires were returned by the post office because the people concerned no longer resided at the addresses. Thus the response rate was $75 \cdot 3 \%$.

In general most aspects of health were evaluated highly by the respondents. Aspects which were valued most were related to healthy eating and sleeping habits, positive feelings, good appearance, regular bowel function, and, the prevention of heart disease and strokes (table I).

Appreciable numbers of respondents (more than $10 \%$ of the sample) were uncertain about eating natural foods; having good social relationships; lowering blood fat levels; "doing things" to prevent dietary deficiencies and bowel and other cancers; and avoiding build up of toxic chemicals, abdominal discomfort, nausea diarrhoea, muscle and joint pains, kidney/ gallstones, and salty, fatty and sugar rich foods.

\section{PRINCIPAL FACTORS ANALYSIS}

The principal factors analysis (with varimax rotation) of these data derived four factors which accounted for $95 \%$ of the explained variance (table II). The major factor which accounted for $71 \%$ of this variance was named, for convenience,

Table III Differences in the perceptions of the importance of aspects of health between

respondents who live alone or with others $1 \%$ rating or with others $1 \%$
"quite" or "very important")

\begin{tabular}{|c|c|c|}
\hline & $\begin{array}{l}\text { Live } \\
\text { alone } \\
(n=49)\end{array}$ & $\begin{array}{l}\text { Live } \\
\text { with others } \\
(n=600)\end{array}$ \\
\hline $\begin{array}{l}\text { 13. Having healthy looking skin } \\
\text { and hair }\end{array}$ & 69 & $59 \star$ \\
\hline $\begin{array}{l}\text { 16. Doing things to prevent dietary } \\
\text { deficiences }\end{array}$ & 69 & $49 \star$ \\
\hline $\begin{array}{l}\text { 17. Doing things to prevent bowel } \\
\text { cancer }\end{array}$ & 73 & $54^{\star}$ \\
\hline $\begin{array}{l}\text { 18. Doing things to prevent other } \\
\text { cancers }\end{array}$ & 75 & $55 t$ \\
\hline $\begin{array}{l}\text { 29. Avoiding salt and salty foods } \\
\text { 30. Avoiding fat and fatty foods }\end{array}$ & $\begin{array}{l}57 \\
54\end{array}$ & $\begin{array}{l}34 \ddagger \\
37^{\star}\end{array}$ \\
\hline
\end{tabular}

${ }^{\star} \mathrm{p}<0.05 ; \mathrm{tp}<0.01 ; \neq \mathrm{p}<0.001$ "avoidance of illness", as the items with the highest factor loadings referred to actions that help avoid illness (table II). Similarly, the second factor was labelled "being healthy" as it appeared to relate to actual states of good health. The third factor was named "healthy lifestyle" because it represented a group of positive specific actions the individual can take to reduce the risk of lifestyle diseases. Finally, the fourth, weakest, factor appeared to link certain nutritional factors to the prevention of cardiovascular disease and cancers, and was named "nutrition and disease".

RESULTS OF THE CONTINGENCY TABLE ANALYSES AND ANALYSES OF VARIANCE OF THE FACTOR SCORES

As might be expected, the results of the two sets of analyses were similar. Results of the contingency table analyses are summarised in tables I, III and IV. There were several groups of differences associated with the demographic variables. These are outlined briefly below.

Sex differences-In general women evaluated most of the items more highly than men. However, although women had higher scores on the "being healthy" factor than men (means: men $=-0.14$, women $=0.08 ; p<0.009$ ) they had significantly lower scores on the "healthy lifestyle" factor (men: 0.23 , women -0.06; $\mathrm{p}<0.007$ ).

Age group differences-Several age group differences were observed (table I). (1) Most aspects of health appeared to become more important as the ages of the respondents increased. (2) This increased evaluation occurred earlier among women (in the 31-50 year age group) than among men (the over fifties). (3) There was a trend among women in the 31-50 year old age group to value personal health more highly than younger or older women (questions 1 , $4,6,8-13,15-20,26,27,30-33)$.

The analysis of variance of the "healthy lifestyle" factor showed that the under 31 year olds valued this most, and the over fifties least (under $31=0.27,31-50=0.07$, over $51=-0.12$; $\mathrm{p}<0.01)$.

SOCIAL STATUS AND EDUCATIONAL GROUP DIFFERENCES

Results of the overall contingency table analyses (table I) showed two complementary trends present in both sexes: with increasing levels of education the smaller was the percentage of 
Table IV Differences in the perceptions of the importance of aspects of health between men with and without children $(\%$ rating "quite" or "very" important). Note:

Thirty-three statements were presented to the respondents; $\chi^{2}$ tests were performed on each item separately for each sex. Only statistically significant differences are shown here.

\begin{tabular}{|c|c|c|}
\hline & $\begin{array}{l}\text { Men with } \\
\text { children } \\
(n=154)\end{array}$ & $\begin{array}{l}\text { Men with } \\
\text { no children } \\
(\mathrm{n}=140)\end{array}$ \\
\hline 2. Eating natural foods & 51 & $30 \pm$ \\
\hline 4. Eating regular meals & 62 & $48^{\star}$ \\
\hline $\begin{array}{l}\text { 7. Having good social relationships } \\
\text { 8. Eating plenty of fruit and }\end{array}$ & 39 & $33^{\star}$ \\
\hline vegetables & 62 & $46 \ddagger$ \\
\hline $\begin{array}{l}\text { 9. Lowering your blood fat levels } \\
\text { 17. Doing things to prevent bowel }\end{array}$ & 43 & $29 \star$ \\
\hline cancer. & 56 & $38 t$ \\
\hline $\begin{array}{l}\text { 18. Doing things to prevent other } \\
\text { cancers }\end{array}$ & 58 & $37 \pm$ \\
\hline 19. Doing things to prevent heart & & \\
\hline $\begin{array}{l}\text { disease/stroke } \\
\text { 20. Avoiding colds and minor }\end{array}$ & 64 & $42 \ddagger$ \\
\hline infections & 39 & $22 \dagger$ \\
\hline 23. Avoiding nausea and/or vomiting & 51 & $37^{\star}$ \\
\hline 22. Avoiding abdominal discomfort & 49 & $32 t$ \\
\hline 24. Avoiding diarrhoea & 52 & $36^{\star}$ \\
\hline 25. Avoiding muscle or joint pains & 47 & $35^{\star}$ \\
\hline
\end{tabular}

respondents who endorsed the "very important" response category, and the greater was the percentage who endorsed the "quite important" category. Thus, with regard to most of the aspects of health, tertiary educated individuals indicated that they were less important than did the other respondents, particularly the primary educated group. The main exception to this general finding was the greater perceived importance of taking regular exercise among technically qualified and tertiary educated people. There was also a lesser tendency for tertiary educated people to indicate greater unimportance/uncertainty of many of the aspects. The differences observed between the three social status groups broadly paralleled the educational differences: increasing social status was associated with decreasing emphasis on the perceived importance of the various aspects of health (table I).

Analysis of the "healthy lifestyle" factor showed that people in high status occupations valued healthy lifestyle activities (eg, taking regular exercise) more than others (high $=0.49$, middle $=0.08$, low $=-0.08 ; p<0.01$ ). This was confirmed by a similar finding associated with educational background (primary $=-0.25$, high school $=0.03$, technical $=0.11$, tertiary $=0.81$; $p<0.001$ ). The tertiary educated respondents had higher "healthy lifestyle" scores than others, particularly those with primary education (and some high school) only.

\section{LIVING ALONE $v$ LIVING WITH OTHERS}

More persons of both sexes who lived alone indicated the following aspects of health were "very important" to them $(p<0.001)$ : healthy looking skin and hair; doing things to prevent dietary deficiencies and bowel and other cancers; and avoiding salty and fatty foods (table III).

A [living arrangements $x$ sex] interaction on the "healthy lifestyle" factor showed that men who lived alone valued those aspects of health most and women living alone valued them least (living alone: $\operatorname{men}=0.59$, women $=-0.42$; living with others: $\operatorname{men}=0 \cdot 20$, women $=-0.06$; $\mathrm{p}<0.05$ ).

\section{PRESENCE OR ABSENCE OF CHILDREN} More men who lived in households with children under 18 years regarded several aspects as "very important" (table IV), compared to men who lived in childless households. These included aspects related to childhood illnesses (nausea) and healthy lifestyle activities. Men with children had higher "healthy lifestyle" scores than other men or women (children absent: $\operatorname{men}=0.04$ women $=-0.07$; children present: $\operatorname{men}=0.43$, women $=-0.08 ; \mathrm{p}<0.05)$.

\section{DIETARY SUPPLEMENTATION}

In general, more of the people who used dietary supplements viewed most aspects of health as "very important", more of those who used them irregularly endorsed the "quite important" category, whereas non-supplementers were less concerned. The supplementer group differences tended to achieve higher levels of statistical significance among women than among men (table I).

These group differences were particularly pronounced on the "being healthy" factor, regular supplementers having higher scores than the other respondents (regular takers $=0.09$, others $=-0.06 ; p<0.02$ ), and on the "healthy lifestyle" factor, irregular supplementers having higher scores than regular or non-supplementers (regular takers $=-0.08$, irregular taker $=0.37$, non-takers $=0.11 ; \mathrm{p}<0.04)$.

\section{Discussion}

COMMUNITY DEFINITIONS OF HEALTH

The results of the factor analysis imply that the community in general evaluates health phenomena along four continua: the avoidance or absence of illness, states of wellbeing, healthy lifestyle, and disease prevention. Although these dimensions depend on the particular aspects of health which were listed, the factors were quite comprehensive and are likely to represent important community perceptions of health.

The derivation of four factors shows that health is not seen as a unidimensional concept and, in particular, that people perceive dimensions in addition to the absence of illness. Further, while some people may value only one dimension highly, others may attach high value to more than one dimension.

\section{ILLNESS EXPERIENCE AND HEALTH} SALIENCE

Generally the observed sociodemographic group differences support the familiarity hypothesis outlined in the introduction. Evaluation of health appeared to be related to the groups' experiences and expectations. The groups' evaluations appeared to parallel their illness experiences. For example, women generally report more symptoms and signs of morbidity than men; ${ }^{8}$ correspondingly, in the present study women evaluated "subjective wellbeing" (factor 2) more highly than men. Similar parallels appear to hold for older and younger age groups ${ }^{7-915}$ and low and high occupational status groups. ${ }^{911} 12$ This apparent relationship between illness experience and evaluations of health requires further investigation.

The social role hypothesis described in the introduction was also supported by the results. Children appeared to impinge on fathers in ways which caused them to place higher valuation on certain aspects of minor children's illnesses (eg, 
nausea) as well as on major adult life threatening diseases such as heart disease (table IV).

The presence of children may make men (fathers) more aware of children's ailments, possibly because they cause inconvenience or because they have to deal with their consequences themselves (eg, comfort a sick child). Children's obvious dependence on their parents may make fathers more aware of their own vulnerability to chronic diseases and the consequences for their children's future.

In general women evaluated health more highly than men. Fathers' evaluations only equalled those of women on the specific aspects referred to above. Thus women's greater evaluation of health may have more to do with feminine sex role socialisation than with direct experience alone.

IMPLICATIONS

The results have several implications for health education, media communications and medical practice.

Health education-The principal finding of the study was that social groups in the community evaluated health in different ways, and in ways which may not always correspond with health professionals' views. Thus health professionals who are concerned mainly with disease prevention are likely to find relatively less receptive audiences among women and younger age groups.

The results suggest the possibility of segmenting members of the community according to their evaluations of health. This is likely to be an important starting point for health education activities. It is important that women's and dietary supplementers' high priorities on subjective wellbeing, older people's concerns about general health, and parents' worries about children's illnesses are anticipated and recognised as legitimate concerns. Many health educators will be familiar with these views but other health professionals who advise the public on health may not be as aware.

Media communication-The possible segmentation of community health interests which the present results offer could be of some value to communicators. They should find it useful to know which interests are shared by various sociodemographic groups and which are peculiar to particular groups. Clearly, individual media communications require their own research into the needs of the intended recipients, but the four dimensions derived from this study are likely to provide useful directions for such work.

The results also confirm the proposition put forward by mass communication theorists $\left(\mathrm{eg}^{17}\right)$ that mass media communications are likely to be perceived differently by different social groups. Men, for example, are less likely than women to look for messages about wellbeing, and younger people are more likely to attend to communications about healthy lifestyle than older people.

The influence of the mass media on people's health evaluations is unclear, but it is likely that certain media are used to bolster existing interests, for example women's magazines routinely deal with topics related to wellbeing. It is also clear that the media can be used to increase the salience of certain aspects of health, such as the value of physical activity or a healthy diet $\left(\mathrm{eg}^{18}\right)$.
Medical practice - Orthodox medical practice is more orientated towards the treatment of signs of physical disease than to subjective wellbeing, healthy lifestyle or prevention. ${ }^{2}$ Orthodox practice does not appear to cater to everyone's health priorities. ${ }^{3}$ It is not surprising then that more women than men opt for alternative health practice with its holistic subjective approach, ${ }^{19}$ and more young people make use of gymnasia and dieting clinics which purport to facilitate healthy lifestyles.

There are sound reasons for suggesting that the recent popularity of alternative health therapies may be undesirable, eg, missing opportunities for the early detection of preventable diseases. Orthodox medicine needs to recognise the legitimacy of the population's perceptions of health and to tailor its services accordingly. Failure to do so may continue the expansion of untested unorthodox therapies.

\section{Conclusion}

This exploratory study has shown that the subjective evaluation of aspects of health is multidimensional and is related to the sociodemographic characteristics of the population. By extension, it appears to be related to illness experience, perceived risk of illness, and role mediated behaviours.

The author thanks Mr D Crawford and Mrs J Gowland for expert technical assistance and Mrs D Gamble for typing the manuscript. The survey reported here was conducted while the author was a Principal Research Scientist at the CSIRO Division of Human Nutrition, Adelaide, supported by a grant from the Commonwealth Department of Health.

1 World Health Organization. Constitution of the World Health Organization. Official Record WHO 1946; 2: 100.

2 Better Health Commission. Looking forward to better health, vol 1. Canberra: Australian Govt Publishing Service, 1986 : 1-2.

3 Maddocks I. Alternative medicine. Med $\mathcal{f}$ Aust 1985; 142 547-51.

4 Gillick MR. Common-sense models of health and disease. $N$ Eng f Med 1985; 313: 700-13.

5 Hunt SM, McEwen J, McKenna SP. Perceived health: age and sex comparisons in a community. $f$ Epidemiol Community Health 1984; 38: 156-60.

6 O'Looney BA, Harding CM. Social class and environment: their perceived influence on health in Britain. Health Educ $\mathcal{F}$ 1984; 43: 89-93.

7 Worsley A, Crawford D. Australian dietary supplementation practices. Research Report No. 1: Health and dietary supplements. Adelaide: CSIRO, Division of Human Nutrition, 1984: 82

8 Wingard D. The sex differential in morbidity, mortality, and lifestyle. Annu Rev Public Health 1984; 5: 433-58.

9 McMichael AJ. Social class (as estimated by occupational prestige) in Australian males in the 1970's. Community Health Stud 1985; 9: 220-30.

10 Black D, Morris JN, Smith C, Townsend P. Inequalities in health: the Black report. Suffolk: Chaucer Press, 1982.

11 Broom DH. The social distribution of illness: is Australia more equal? Soc Sci Med 1984; 18: 909-17.

12 Broadhead P. Social status and mortality in Australia. Community Health Stud 1985; 9: 87-98.

13 Dillman DA. Mail and telephone surveys: the total design method. New York: John Wiley, 1978.

14 Worsley A. Perceived reliability of sources of health information. Health Educ Res Theor Pract 1989; 4: 367-76.

15 Worsley A, Crawford D. Australian dietary supplementation practices: health and dietary supplements. Med f Aust 1984; 140: 579-83.

16 Kim JO. Factor analysis: statistical methods and practical issues. Beverley Hills, California: Sage, 1975 .

17 McCron R, Budd J. Mass communication and health education. Leicester: Centre for Mass Communication Research, University of Leicester, 1978.

18 Maccoby N, Farquhar JW. Communication for health: unselling heart disease. $\mathcal{f}$ Communication 1975; 25: 114-26.

19 Social Development Committee. Inquiry into alternative medicine and the health food industry. Melbourne: Parliament of Victoria, 1986; 30, 53. 